\title{
Evaluation of the antioxidant potentials of extract and fractions of Vitex doniana fruit and identification of the bioactive metabolites using HPLC-DAD-MS analysis
}

Keziah Uchechi Ajah 1, *, Ozioma Anne Asomugha 1, Chinazom Perpetua Ifedigbo 1, Kosoluchukwu Chidubem Umeh 1, Onyeka Chinwuba Obidiegwu ${ }^{1}$, Amara Anwuchaepe Ajaghaku ${ }^{2}$, Nkeoma Nkasi Okoye ${ }^{3}$, Moses Aziakpono Omoriri ${ }^{4}$ and Festus Basden Chiedu Okoye ${ }^{1}$

\author{
${ }^{1}$ Department of Pharmaceutical and Medicinal Chemistry, Faculty of Pharmaceutical Sciences, Nnamdi Azikiwe University, \\ Awka, Anambra State Nigeria. \\ 2 Department of Pharmacognosy, Faculty of Pharmaceutical Sciences, Enugu State University of Science and Technology, \\ Agbani, Enugu State Nigeria. \\ ${ }^{3}$ Department of Pure and Industrial Chemistry, Faculty of Physical Sciences, Nnamdi Azikiwe University, Awka, Anambra \\ State Nigeria. \\ ${ }^{4}$ Department of Pharmacology and Toxicology, Federal University Oye-Ekiti, Ekiti State, Nigeria.
}

GSC Biological and Pharmaceutical Sciences, 2021, 17(01), 160-175

Publication history: Received on 12 September 2021; revised on 15 October 2021; accepted on 17 October 2021

Article DOI: https://doi.org/10.30574/gscbps.2021.17.1.0310

\begin{abstract}
Isoflavones and flavonoids in general found in fruits and vegetable act as natural antioxidants. This study was aimed at screening the isoflavone-rich fractions of Vitex doniana fruit extract for antioxidant activity using in vitro and in vivo models. The ethyl acetate and butanol fractions were screened for in vitro antioxidant activity by DPPH free radical scavenging and FRAP (Fe3+ Reducing Antioxidant Power) assays using ascorbic acid as standard. In vivo antioxidant activity was also tested against carbon tetrachloride-induced toxicity in mice using carbon tetrachloride (4 mL/kg) and silymarin $(100 \mathrm{mg} / \mathrm{kg})$ as standard. The ethyl acetate fraction and butanol Vacuum Liquid Chromatography (VLC) subfractions were subjected to High Performance Liquid Chromatography-Diode Array Detector (HPLC-DAD) and Liquid Chromatography-Mass Spectrometry (LC-MS) analyses. The ethyl acetate and butanol fractions inhibited DPPH radicals with an $\mathrm{IC}_{50}$ of $897 \mu \mathrm{g} / \mathrm{mL}$ and $2809.38 \mu \mathrm{g} / \mathrm{mL}$ respectively. Both fractions also showed mild FRAP result with EC50 of $1401 \mu \mathrm{g} / \mathrm{mL}$ and $7051 \mu \mathrm{g} / \mathrm{mL}$ respectively. The fractions produced significant decrease $(\mathrm{P}<0.05)$ in ALP levels only while ethyl acetate fraction caused a significant reduction in the value of only malondialdehyde. Both fractions also increased levels of superoxide dismutase (SOD). HPLC-DAD analysis led to the detection of cinnamic acid, protocatechuic acid and two isoflavones daidzein and genistein. Further LC-MS analysis confirmed the presence of the isoflavones tectorigenin, 5-0-methylgenistein, and 5-0-methyltectorigenin, among other flavonoids, peonidin, 5methylpeonidin, methylmalvidin and kaempferol-3-0-(2"'galloyl)-glucopyranoside. The detected isoflavones and other flavonoids may contribute to the observed mild in vitro and good in vivo antioxidant activity of $V$. doniana fruit extract and fractions.
\end{abstract}

Keywords: Vitex doniana; Antioxidant activity; HPLC-DAD; LC-MS; Isoflavones

\section{Introduction}

Currently, oxidative stress has attracted the attention of many researchers due to the ability of free radicals to affect all the three important classes of biological molecules including nucleic acids (DNA and RNA), proteins, and lipids thus

\footnotetext{
${ }^{*}$ Corresponding author: Keziah Uchechi Ajah

Department of Pharmaceutical and Medicinal Chemistry, Faculty of Pharmaceutical Sciences, Nnamdi Azikiwe University, Awka, Anambra State Nigeria.
}

Copyright ( 12021 Author(s) retain the copyright of this article. This article is published under the terms of the Creative Commons Attribution Liscense 4.0 
implicated in the pathophysiology of different diseases [1]. Oxidative stress is counteracted by either naturally generated (endogenous antioxidants), or externally supplied through foods (exogenous antioxidants). Most antioxidants are derived from dietary sources including vegetable, meat, fish, and fruits. Therefore, consumption of plants containing antioxidant components is recommended to increase protective ability of living systems against oxidative damage. Flavonoids are polyphenolic compounds which are present in most plants and known for their potent antioxidant activity [2]. A lot of natural products are being investigated to discover bioactive molecules that show promising antioxidant potential.

In the discovery of new bioactive natural products, dereplication of crude extracts is of utmost importance in order to avoid the tedious isolation of known constituents and generate knowledge for structure determination [3]. Hyphenated techniques, which is the combination of separation technologies with spectroscopic techniques has been demonstrated as a powerful means for both quantitative and qualitative analysis of known and unknown compounds in complex natural product extracts or fractions. For natural product analysis, usually the dereplication procedure relies mainly on LC-UV-DAD and LC-MS, LC-MS-MS or LC-MSn. Because of the high sensitivity and selectivity of LC-MS, natural products can be efficiently detected in the complex chromatograms obtained with crude extracts. MS provides information on the molecular weight as well as the fragmentation pattern of the analyte molecules which is invaluable for confirming the identities of these analytes [4].

Vitex is a genus of flowering plants that belong to the family Verbanaceae known locally as mbembe (Igbo); black plum (English); dinya (Hausa); oori-nla or oriri (Yoruba) [5,6]. There is a lot of information pointing to the fruit as having more potential than is known. Despite its use as food in some parts of West Africa, there is limited published research report about certain bioactivities of the fruit. Some research has been carried out on some parts of the plant including the leaves [7] and seeds [8]. Some studies have also been done on the fruit's proximate composition, mineral contents, sugar and anti-nutrient contents [9]. For balanced documentation, it is important that information on antioxidant activity as well as the secondary metabolites present in the edible fruit is provided. The present study was undertaken to assess the antioxidant potentials of Vitex doniana fruit extracts and fractions using in vitro techniques like the DPPH scavenging and ferric reducing antioxidant power (FRAP) models. We also validated the antioxidant potential on in vivo mouse model using carbon tetrachloride as a hepatotoxin to provide evidence for its claims in folklore practice. The identities of the bioactive secondary metabolites were also determined using HPLC-DAD and HPLC-ESI-MS analyses.

\section{Material and methods}

\subsection{Plant materials and preparation of extracts and fractions}

\subsubsection{Preparation of plant material and extraction}

Fresh samples of the fruits of Vitex doniana were purchased from different vendors from Eke Awka market in Awka, Anambra State, Nigeria in the month of August 2017, when the fruits were in season. The fruit was authenticated by Mr. Patrick Ugwuozo, a Taxonomist of the Department of Botany, Nnamdi Azikiwe University, Awka, Nigeria and a voucher specimen (PCG 474/A/021) was deposited at the herbarium of Department of Pharmacognosy and Traditional Medicine of the same University. The edible pulp was removed manually with a knife, air dried at room temperature for twentyeight (28) days and pulverized into coarse powder with a grinding machine. $800 \mathrm{~g}$ of air-dried pulverized fruit was coldmacerated with $5 \mathrm{~L}$ of methanol for $72 \mathrm{~h}$, filtered off and the solvent evaporated under reduced pressure to obtain crude methanol extract.

\subsubsection{Liquid-liquid fractionation}

$149 \mathrm{~g}$ of crude methanol extract was successively partitioned against $\mathrm{n}$-hexane, ethylacetate and n-butanol to obtain the respective fractions in a $1 \mathrm{~L}$ separating funnel. This was done using $500 \mathrm{~mL}$ of each solvent per run and repeated four times. A total of $2 \mathrm{~L}$ of each solvent was used. The various fractions were concentrated at temperature of $45^{\circ} \mathrm{G} 5^{\circ} \mathrm{Cusing}$ a rotary evaporator.

\subsubsection{Vacuum liquid chromatography}

$5 \mathrm{~g}$ of butanol fraction was triturated with some silica gel and introduced into the VLC column (5 L) sintered column packed with 100 g silica gel (200-400 mesh, $30 \mathrm{~cm}$ length $\times 3 \mathrm{~cm}$ internal diameter) as the stationary phase. The column was eluted with $500 \mathrm{~mL}$ each of a mixture of hexane:ethyl acetate $(9: 1,8: 2,7: 3,6: 4,5: 5,4: 6,3: 7,2: 8,1: 9,0: 10)$ and thereafter eluted with $500 \mathrm{~mL}$ each of mixture of dichloromethane: methanol $(10: 0,3: 7,5: 5,7: 3,0: 10)$. The fractions obtained were collected separately and concentrated using the rotary evaporator to produce fractions VTX-F to VTX-

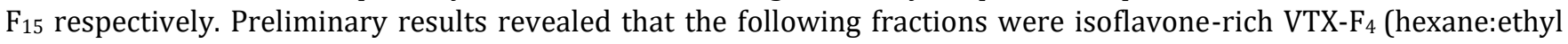


acetate, 6:4), VTX-F5 (hexane:ethyl acetate, 5:5), VTX-F 6 (hexane:ethyl acetate, 4:6) and VTX-F (hexane:ethyl acetate, 3:7). The VLC was done specifically for the purpose of HPLC-DAD and HPLC-MS analyses.

\subsection{High-performance liquid chromatography-diode-array detection (HPLC-DAD) assay}

HPLC analysis was carried out on the ethylacetate fraction and the four butanol sub-fractions with a Dionex P580 HPLC system coupled to a photodiode array detector (UVD340S, DionexSoftron GmbH, Germering, Germany). Detection was at 235, 254, 280 and $340 \mathrm{~nm}$. The separation column $(125 \times 4 \mathrm{~mm}$; length $\times$ internal diameter $)$ was prefilled with Eurospher-10 C18 (Knauer, Germany), and a linear gradient of nanopure water (adjusted to pH 2 by addition of formic acid) and methanol was used as eluent. The absorption peaks for each of the five extracts were analyzed by comparing with those in the HPLC-ultraviolet (UV)/visible database, which contains over 1600 registered compounds.

\subsection{Liquid chromatography - mass spectroscopy (LC-MS)}

The four butanol sub-fractions were further subjected to Liquid Chromatography-Electrospray Ionization Mass Spectroscopy (LC-ESI/MS) using a ThermoFinningan LCQ-Deca mass spectrometer (Germany) connected to an UV detector. The samples were dissolved in $\mathrm{MeOH}$ and injected to the HPLC/ESI-MS set up. A solution of the sample is then sprayed at atmospheric pressure through a $2-5 \mathrm{kV}$ potential. HPLC was run on a Eurospher C-18 ( 6 × $2 \mathrm{~mm}$, i.d.) reversed phase column. The mobile phase was $0.1 \%$ Formic acid solution in nanopure water (A), to which MeOH (B) was added by a linear gradient. The flow rate was $400 \mu \mathrm{L} / \mathrm{min}$ and the absorbance detected at $254 \mathrm{~nm}$. ESI (electrospray ionization) was performed at a capillary temperature of $2000 \mathrm{C}$ and drift voltage of $20 \mathrm{eV}$. MS/MS experiments were also carried out on the molecular ion to obtain daughter ions which are diagnostic of the compounds. The constituents were determined by comparison of the molecular and fragments ions with literature values.

\subsection{In vitro antioxidant assay}

\subsubsection{DPPH free radical scavenging activity}

The DPPH assay was performed using the method described by Okpongete et al [10]. Freshly prepared DPPH solution $(0.5 \mathrm{~mL}, 0.6 \mathrm{mmol})$ was added to $0.5 \mathrm{~mL}$ of different concentrations of the fractions $(7.8125,15.625,31.25,62.5,125$, 250, 500 and $1000 \mu \mathrm{g} / \mathrm{mL}$ ). The volume of the solution was adjusted with methanol to a final volume of $5 \mathrm{~mL}$. The control tube contained $4.5 \mathrm{~mL}$ methanol and $0.5 \mathrm{~mL}$ of DPPH solution. After incubation in the dark for $30 \mathrm{~min}$ at room temperature, absorbance was taken at $517 \mathrm{~nm}$. Ascorbic acid was used as standard. The DPPH radical percentage scavenging potentials was calculated from the equation below.

$$
\% \text { Inhibition of free radical }=\left(A_{0}-A_{t} / A_{0}\right) \times 100
$$

Where $A_{0}$ is the absorbance of the control, and $A_{t}$ is the absorbance of the test/standard.

\subsubsection{Ferric reducing antioxidant power (FRAP)}

Ferric reducing antioxidant power of the fractions was measured according to the method proposed by Benzie and Strain [11]. FRAP reagent was prepared by mixing in $25 \mathrm{~mL}$ acetate buffer (30 mM; pH 3.6), 2.5 mL TPTZ (2,4,6tripyridyl-s-triazine) solution (10 mM) and $2.5 \mathrm{~mL}$ ferric chloride solution (20 mM). The mixture was incubated for 15 min at $37^{\circ} \mathrm{C}$ before use. Ascorbic acid was employed as a standard in the assay and its calibration curve obtained by using concentration ranging from $50 \mathrm{mg} / \mathrm{L}$ to $500 \mathrm{mg} / \mathrm{L}$ in water. To $2.85 \mathrm{~mL}$ FRAP reagent in a test tube, $150 \mu \mathrm{L}$ fraction $(0.1 \mathrm{mg} / \mathrm{mL}$ in methanol) or standard was added. The mixture was incubated for $30 \mathrm{~min}$ in the dark and its absorbance measured at $593 \mathrm{~nm}$. The blank contained an equal volume of methanol instead of the plant sample. The results were reported as $\mu \mathrm{g}$ of ascorbic acid equivalents (AAE) per $\mathrm{mL}$.

\subsection{Acute toxicity test}

Acute toxicity, $\mathrm{LD}_{50}$ test was carried out using modified Lorke's method (1983) [12]. A total of 13 mice weighing $30 \mathrm{~g}$ on average were fasted overnight prior to this study and used in two phases.

- Phase 1: The mice were divided into 3 groups of 3 mice each, and the extract was administered at three dose level $(10,100$ and $1000 \mathrm{mg} / \mathrm{kg})$ body weight. The animals were then monitored for $24 \mathrm{~h}$.

- Phase 2: Absence of deaths in the first phase led to the use of 2000, 3000, 4000 and $5000 \mathrm{mg} / \mathrm{kg} \mathrm{dose} \mathrm{of} \mathrm{extract}$ for 4 groups of 1 animal each. Animals in each group were also observed for obvious toxic signs and mortality $24 \mathrm{~h}$ post administration. 


\subsection{In vivo antioxidant assay}

\subsubsection{Animals}

Seventy-four (74) male and female Swiss albino mice weighing between 20-30 g were obtained from the laboratory animal facility of the Department of Pharmacology and Toxicology, Faculty of Pharmaceutical Sciences, Nnamdi Azikiwe University, Awka, Anambra state, Nigeria. They were housed in clean metal cages, supplied portable water and fed with commercial pelleted feed (Guinea Feed $\AA$, Nigeria). Animals were handled in compliance with the National Institute of Health Guidelines for care and use of laboratory animals (Pub No. 85-23, revised 1985).

\subsubsection{Experimental design for in vivo antioxidant screening}

The in vivo antioxidant activity of the plant extracts was tested using carbon tetrachloride $\left(\mathrm{CCl}_{4}\right)$ model. Silymarin $(100$ $\mathrm{mg} / \mathrm{kg}$ ) was used as a standard drug in this study. Silymarin is a flavonolignan that has been introduced fairly recently as a hepatoprotective agent. The mice were divided randomly into seven groups according to the following protocol.

- Group I: Normal (uninduced) control ( $n=7$, the animals were given normal saline only)

- Group II: Hepatotoxic control ( $\mathrm{n}=7$, the animals were given only $4 \mathrm{~mL} / \mathrm{kg} \mathrm{CCl}_{4}$ ).

- Group III: Treatment control (n=7, the animals were given Silymarin $100 \mathrm{mg} / \mathrm{kg}$ and $4 \mathrm{~mL} / \mathrm{kg}$ of $\mathrm{CCl} 4$ )

- Groups IV and V: Treatment groups (n=7 in each case, the animals were given $250 \mathrm{mg} / \mathrm{kg}$ and $500 \mathrm{mg} / \mathrm{kg}$ of butanol fraction respectively and $\left.4 \mathrm{~mL} / \mathrm{kg} \mathrm{CCl}_{4}\right)$.

- Groups VI and VII: Treatment groups (n=7 in each case, the animals were given $250 \mathrm{mg} / \mathrm{kg}$ and $500 \mathrm{mg} / \mathrm{kg}$ of ethyl acetate fraction respectively and $4 \mathrm{~mL} / \mathrm{kg}$ of $\mathrm{CCl}_{4}$ ).

The mice were treated as per the treatment protocol for a period of $7 \mathrm{~d}$. On the eighth day, oxidative stress was induced by administration of $\mathrm{CCl}_{4}(4 \mathrm{ml} / \mathrm{kg})$ orally.

\subsubsection{Biochemical assay of serum liver marker enzymes}

After treatment, the animals were anesthetized using chloroform and blood collected retro-orbitally into a plain tube. The blood was centrifuged at $3000 \mathrm{rpm}$ for $10 \mathrm{~min}$ and the serum obtained for the determination of liver biomarkers using manufacturers' (Randox and Teco) kits leaflets procedures with little modification. Aspartate aminotransferase (AST) and alanine aminotransferase (ALT) were determined according to the method of Reitman and Frankel [13] while alkaline phosphatase (ALP) was determined according to the method of Roy [14].

\subsubsection{Assessment of liver antioxidant enzyme activity and lipid peroxidation of the fractions}

A portion of the liver was harvested through surgical dissection and homogenized with ice cold $0.05 \mathrm{M}$ sodium phosphate buffer ( $\mathrm{pH} \mathrm{7.0)}$ and centrifuged at $12,000 \mathrm{rpm}$ for $20 \mathrm{~min}$ at $4^{\circ} \mathrm{C}$. The supernatant was decanted and stored at $4^{\circ} \mathrm{C}$ for the determination of liver antioxidant enzyme superoxide dismutase and lipid peroxidation. Superoxide dismutase activity was evaluated by its ability to inhibit the auto-oxidation of epinephrine as described by Misra and Fridovich [15] with little modification. Lipid peroxidation was evaluated using the method of Gutteridge and Wilkins [16].

\subsection{Statistical analysis}

Data obtained from the study were analyzed using Statistical Package for Social Sciences (SPSS-20). Results were presented as mean \pm Standard error of mean (SEM) of sample replicates. Raw data were subjected to one-way analyses of variance (ANOVA) followed by post hoc turkey's test. $\mathrm{p}<0.05$ was considered to be statistically significant.

\section{Results}

\subsection{Extraction yield of plant material}

$149 \mathrm{~g}(18.6 \% \mathrm{w} / \mathrm{w})$ of crude methanol extract was recovered from $800 \mathrm{~g}$ of powdered fruit pericarp. Weight of fractions and their yields calculated from $149 \mathrm{~g}$ of crude methanol extract are: ethyl acetate fraction $(12.1 \mathrm{~g}, 8.1 \% \mathrm{w} / \mathrm{w})$, butanol fraction (37.54 g, 25.2\% w/w) and n-hexane fraction with the lowest yield (5.96 g, 4\% w/w). 


\subsection{In vitro antioxidant effect of the fractions}

The result of the in vitro antioxidant assay is presented in Tables 1 and 2 below. The ethyl acetate and butanol fractions exhibited a comparable antioxidant activity with that of standard ascorbic acid at varying concentrations tested with ethyl acetate fraction having better activity. The FRAP result revealed that the positive control, ascorbic acid showed best ferric reducing property with $\mathrm{EC}_{50}$ of $1350.53 \mu \mathrm{g} / \mathrm{mL}$ followed by ethyl acetate fraction having an $\mathrm{EC}_{50}$ of $1401 \mu \mathrm{g} / \mathrm{mL}$. Butanol fraction showed a result of $7051 \mu \mathrm{g} / \mathrm{mL}$.

Table 1 Inhibitory concentration $\left(\mathrm{IC}_{50}\right)$ of samples against DPPH

\begin{tabular}{|c|c|}
\hline Sample & $\mathrm{IC}_{50}(\mu \mathrm{g} / \mathrm{mL}) \pm \mathrm{SD}$ \\
\hline Ascorbic acid & $13.29 \pm 1.75$ \\
\hline Butanol fraction & $2809.38 \pm 224.92$ \\
\hline Ethylacetate fraction & $897.04 \pm 105.6$ \\
\hline
\end{tabular}

SD: Standard deviation

Table 2 Effective concentration of ( $\left.\mathrm{EC}_{50}\right)$ of samples in FRAP

\begin{tabular}{|c|c|}
\hline Sample & $\mathrm{EC}_{50}(\mu \mathrm{g} / \mathrm{mL}) \pm \mathrm{SD}$ \\
\hline Ascorbic acid & $1401.61 \pm 72.24$ \\
\hline Butanol fraction & $7051.98 \pm 662.88$ \\
\hline Ethylacetate fraction & $1661.55 \pm 21.9$ \\
\hline
\end{tabular}

\subsection{Acute toxicity}

Result of oral acute toxicity study in mice revealed no lethality or toxic reactions at any of the selected doses, showing that the $\mathrm{LD}_{50}$ of the fraction is above $5000 \mathrm{mg} / \mathrm{kg}$.

\subsection{Effect of administration of the fractions on liver biomarkers}

The effects of the butanol and ethyl acetate fractions of $V$. doniana on liver biomarkers alanine aminotransferase (ALT), aspartate aminotransferase (AST) and alkaline phosphatase (ALP) levels in $\mathrm{CCl}_{4}$-induced liver damage in mice are summarized in Table 3. Administration of $\mathrm{CCl}_{4}$ resulted in a significant $(\mathrm{P}<0.05)$ elevation of hepatospecific serum markers ALT, AST and ALP in $\mathrm{CCl}_{4}$ - treated group (Group II), when compared with the normal control group (Group I). When the test fractions (Groups IV to VII) and silymarin (Group III) were administered, the levels of the enzyme ALP decreased significantly $(\mathrm{P}<0.05)$ compared to the $\mathrm{CCl}_{4}$-treated group. This was observed for both ethylacetate and butanol fractions.

\subsection{Effect of administration of the fractions on oxidative stress markers}

Table 3 Effects of fractions of Vitex doniana fruits on liver biomarkers of albino mice induced with carbon tetrachloride

\begin{tabular}{|c|c|c|c|c|}
\hline Group & Dose (mg/kg) & $\operatorname{ALT}(U / L)$ & AST (U/L) & ALP (IU/L) \\
\hline Normal control & - & $12.69 \pm 1.94$ & $42.62 \pm 2.49$ & $11.69 \pm 2.06$ \\
\hline $\mathrm{CCl}_{4}$ control & $4 \mathrm{ml} / \mathrm{kg}$ & $47.33 \pm 0.87^{*}$ & $95.49 \pm 3.46^{*}$ & $24.71 \pm 2.79 *$ \\
\hline Silymarin $+\mathrm{CCl}_{4}$ & 100 & $49.19 \pm 1.40^{*}$ & $96.02 \pm 2.72^{*}$ & $18.06 \pm 1.48$ \\
\hline $\mathrm{BF}+\mathrm{CCl}_{4}$ & 250 & $50.39 \pm 0.18^{*}$ & $100.73 \pm 0.49 *$ & $17.59 \pm 2.56$ \\
\hline $\mathrm{BF}+\mathrm{CCl}_{4}$ & 500 & $51.29 \pm 0.40^{*}$ & $99.57 \pm 1.36^{*}$ & $14.21 \pm 1.82^{\mathrm{a}}$ \\
\hline $\mathrm{EF}+\mathrm{CCl}_{4}$ & 250 & $50.95 \pm 0.54^{*}$ & $97.90 \pm 1.92^{*}$ & $13.38 \pm 1.66^{\mathrm{a}}$ \\
\hline $\mathrm{EF}+\mathrm{CCl}_{4}$ & 500 & $50.67 \pm 0.41^{*}$ & $99.36 \pm 0.71^{*}$ & $12.12 \pm 1.70^{a}$ \\
\hline
\end{tabular}


The effects of the butanol and ethyl acetate fractions of $V$. doniana fruit on the activities of oxidative stress markers malondialdehyde (MDA) and superoxide dismutase (SOD) are presented in Table 4. A significant increase in the levels of MDA was observed in the liver of $\mathrm{CCl}_{4}$ treated groups when compared to the normal control. Pretreatment with the fractions showed a marked reduction in MDA levels with $500 \mathrm{mg} / \mathrm{kg}$ of ethyl acetate fraction and Silymarin (100 mg/kg) showing significant reduction in MDA values. There was a marked decrease in SOD activity of animals treated with $\mathrm{CCl}_{4}$. Pretreatment with the fractions however showed restoration of the antioxidant enzymes.

\subsection{Result of High-performance liquid chromatography-diode-array detection (HPLC-DAD) analysis.}

The HPLC-DAD analysis of the extracts suggested the presence of cinnamic acid, daidzein, protocatechuic acid and genistein. The HPLC chromatograms, UV-spectra, and chemical structures of detected compounds are presented in Figures 1-4, respectively.

Table 4 Effects of fractions of Vitex doniana fruits on liver enzymes of albino mice induced with carbon tetrachloride

\begin{tabular}{|c|c|c|c|}
\hline Group & Dose (mg/kg) & MDA (nmol/mL) & SOD $(\mathrm{U} / \mathrm{mL})$ \\
\hline Normal control & - & $0.81 \pm 0.22$ & $0.96 \pm 0.08$ \\
\hline $\mathrm{CCl}_{4}$ control & $4 \mathrm{ml} / \mathrm{kg}$ & $3.54 \pm 0.62^{*}$ & $0.92 \pm 0.08$ \\
\hline Silymarin $\mathrm{CCl}_{4}$ & 100 & $1.19 \pm 0.17^{a}$ & $0.67 \pm 0.11$ \\
\hline $\mathrm{BF}+\mathrm{CCl}_{4}$ & 250 & $2.47 \pm 0.37$ & $1.23 \pm 0.16$ \\
\hline $\mathrm{BF}+\mathrm{CCl}_{4}$ & 500 & $2.47 \pm 0.31$ & $1.14 \pm 0.03$ \\
\hline $\mathrm{EF}+\mathrm{CCl}_{4}$ & 250 & $2.06 \pm 0.54$ & $1.10 \pm 0.16$ \\
\hline $\mathrm{EF}+\mathrm{CCl}_{4}$ & 500 & $1.91 \pm 0.29^{a}$ & $1.10 \pm 0.11$ \\
\hline
\end{tabular}
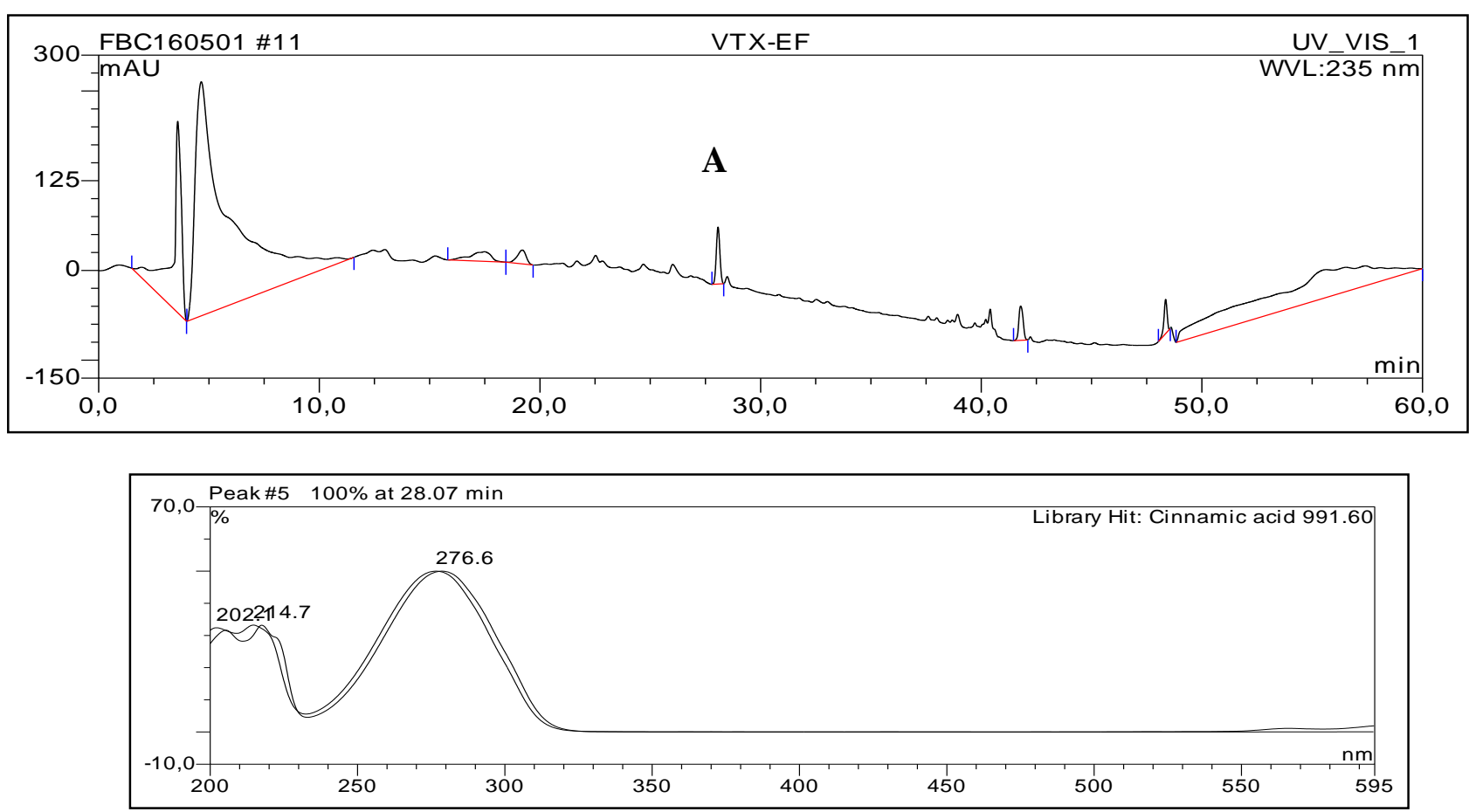

(A: Cinnamic acid)

Figure 1 HPLC Chromatogram of Fraction VTX-EF showing the detected and identified compound, Cinnamic acid (A) and its UV (DAD) spectrum. 

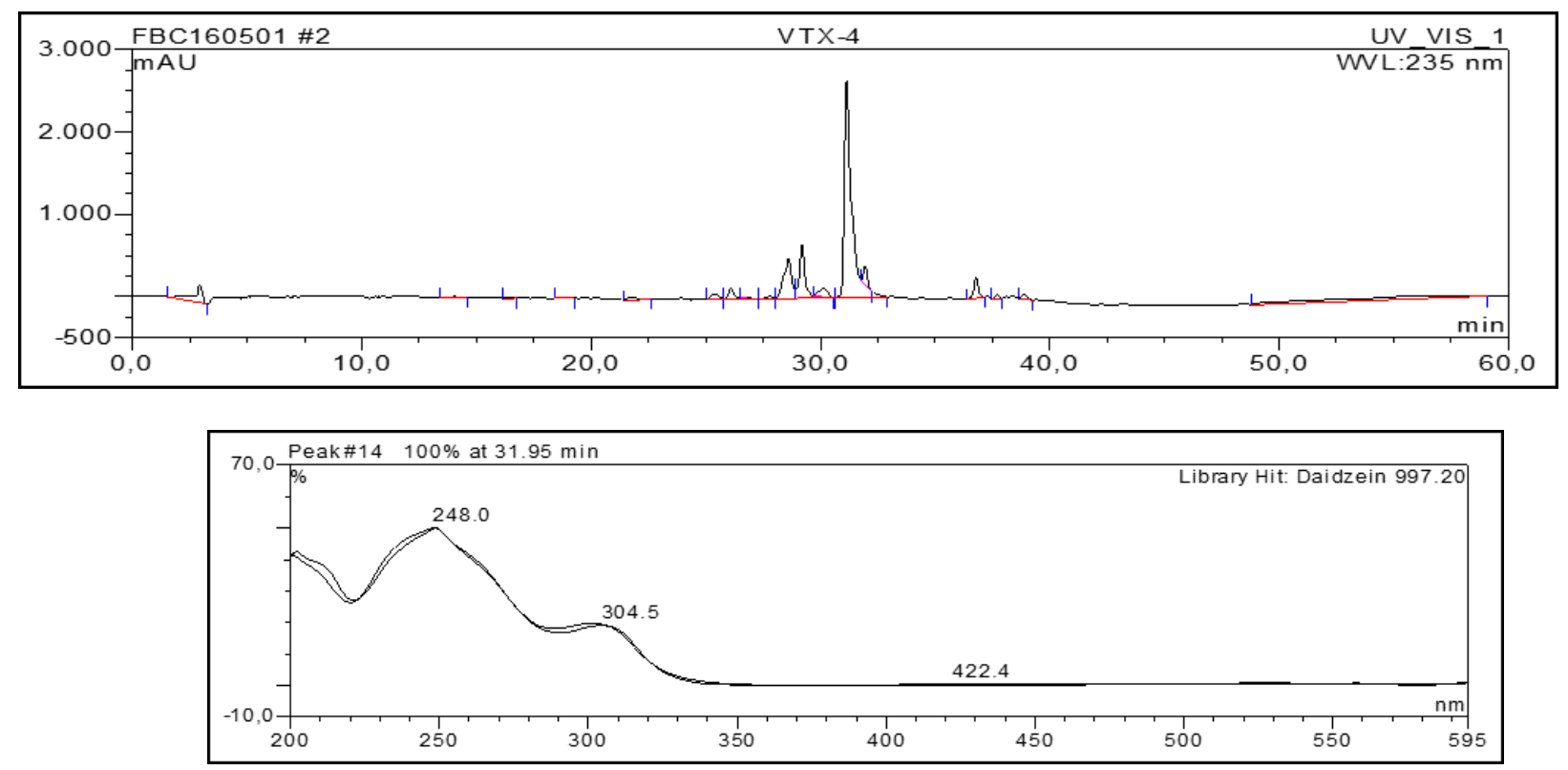

(B: Daidzein)

Figure 2 HPLC Chromatogram of Fraction VTX-F showing the detected and identified isoflavone: Daidzein (B) and its UV (DAD) spectrum
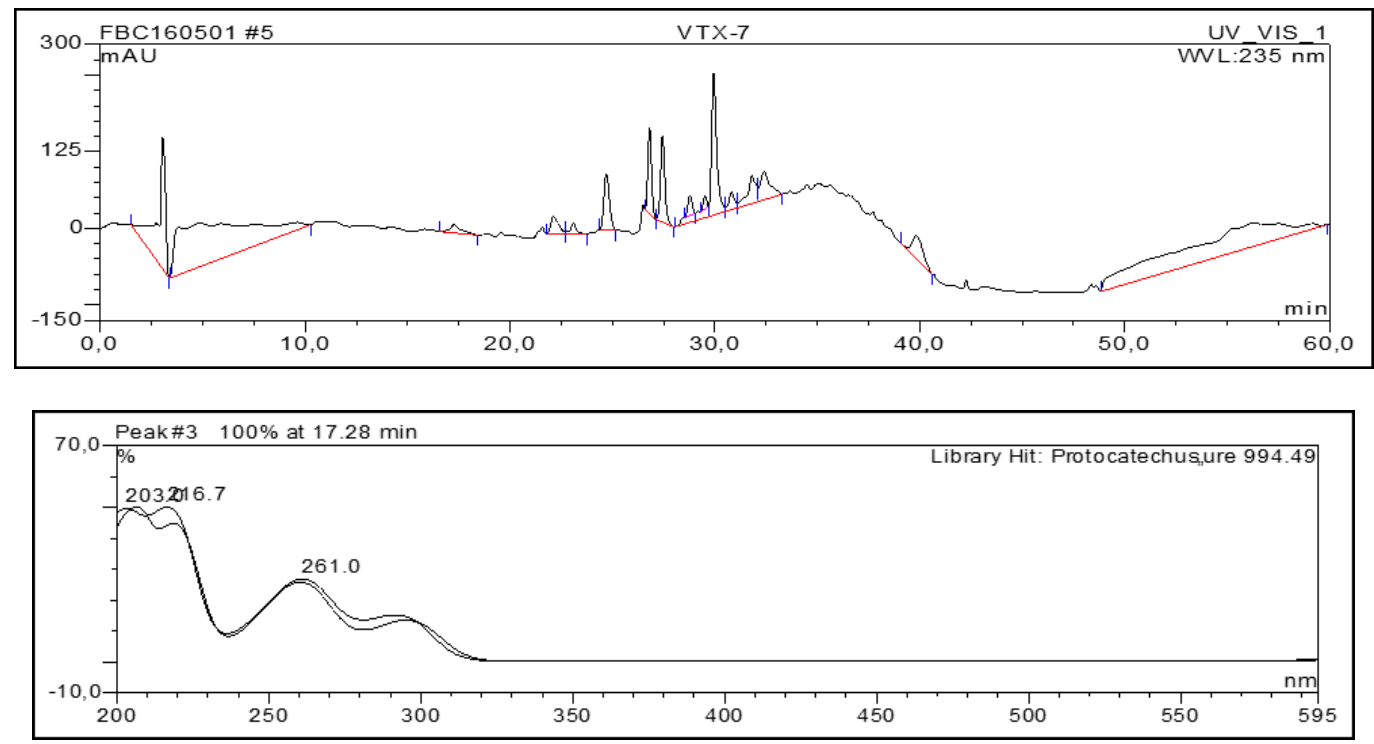

(C: Protocatechuic acid)

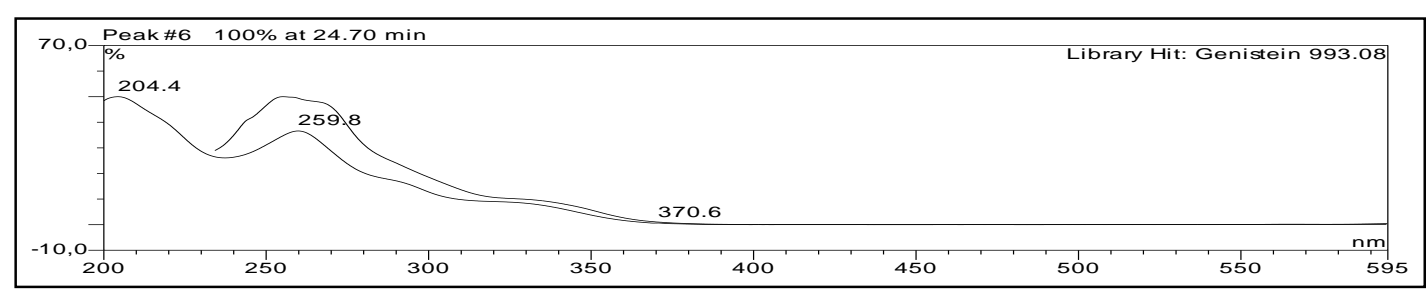

(D: Genistein)

Figure 3 HPLC Chromatogram of Fraction VTX-F7 showing the detected and identified phenolic acid, Protocatechuic acid (C), and the isoflavone, Genistein (D) and their UV (DAD) spectra 


\subsection{Result of Liquid chromatography - mass spectroscopy (LC-MS) analysis}

The MS spectra of the four butanol sub-fractions are given in Figures S1 - S4 in the supplementary document. The identities, pseudomolecular and characteristic fragment ion peaks for the individual detected compounds are listed in the Table 5. The structures of the compounds identified are also shown in Figure 4.These compounds were identified on the basis of careful analysis of their MS fragmentation patterns and by comparison of their MS spectral data with those previously reported in the literature.

Table 5 HPLC-DAD and ESI-MS data of the detected compounds from Vitex doniana

\begin{tabular}{|c|c|c|c|c|c|c|c|c|}
\hline Fraction & $\begin{array}{c}T_{R} \\
(\min )\end{array}$ & $\begin{array}{c}\mathrm{UV} \\
\lambda_{\max } \\
(\mathrm{nm})\end{array}$ & $\begin{array}{c}\text { Molar } \\
\text { mass }\end{array}$ & $\begin{array}{c}{[\mathrm{M}+\mathrm{H}]+} \\
(\mathrm{m} / \mathrm{z})\end{array}$ & $\begin{array}{c}\text { Fragment } \\
\text { ions (+) }\end{array}$ & $\begin{array}{l}{[\mathrm{M}-\mathrm{H}]^{-}} \\
(\mathrm{m} / \mathrm{z})\end{array}$ & $\begin{array}{c}\text { Fragment } \\
\text { ions(-) }\end{array}$ & $\begin{array}{c}\text { Compound } \\
\text { identities }\end{array}$ \\
\hline \multirow[b]{2}{*}{$\stackrel{\substack{5 \\
⿱ 亠 乂}}{x}$} & 22.85 & 282.0 & 330 & 331.2 & - & 329.2 & & ND \\
\hline & 23.76 & 262.0 & 300 & 301.3 & $\begin{array}{c}323(\mathrm{M}+23) \\
622.7 \\
(2 \mathrm{M}+23) \\
\end{array}$ & 299.2 & $\begin{array}{r}598.9 \\
(2 \mathrm{M}-1) \\
\end{array}$ & Tectorigenin \\
\hline \multirow{5}{*}{ 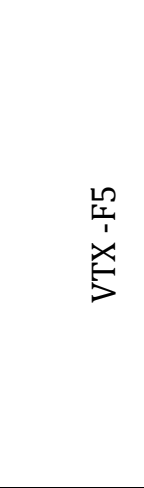 } & 21.93 & 262.0 & 314 & 315.2 & - & 313.2 & - & ND \\
\hline & 22.41 & 250.0 & 284 & 285.2 & $\begin{array}{c}307.1 \\
(M+23) \\
590.9 \\
(2 M+23)\end{array}$ & 283.2 & - & 5-0-Methylgenistein \\
\hline & 22.79 & 258.0 & 330 & 331.2 & - & 329.2 & $\begin{array}{c}658.4 \\
(2 \mathrm{M}-2)\end{array}$ & $\begin{array}{l}\text { 5-0-Methyl } \\
\text { tectorigenin }\end{array}$ \\
\hline & 23.83 & 262.0 & 300 & 301.2 & - & 299.3 & - & Tectorigenin \\
\hline & 24.77 & 244.0 & 298 & 299.2 & $\begin{array}{c}618.6 \\
(2 M+23)\end{array}$ & 297.2 & $\begin{array}{c}594.8 \\
(2 \mathrm{M}-1)\end{array}$ & ND \\
\hline \multirow{4}{*}{ 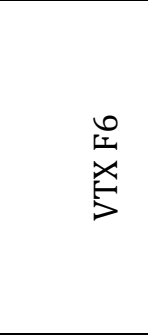 } & 21.47 & 252.0 & 344 & 345.2 & - & 343.3 & - & Methylmalvidin \\
\hline & 21.75 & 243.0 & 314 & 315.3 & $\begin{array}{c}337.2 \\
(M+23) \\
650.8 \\
(2 M+23)\end{array}$ & 313.3 & - & 5-Methylpeonidin \\
\hline & 22.63 & 258.0 & & - & - & - & - & ND \\
\hline & 23.75 & 264.0 & 300 & 301.3 & & 299.3 & - & Peonidin \\
\hline \multirow{4}{*}{ 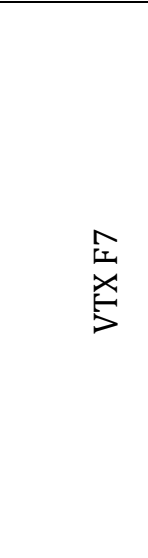 } & 20.04 & 258 & 330 & 331.2 & $\begin{array}{c}353.1 \\
(\mathrm{M}+23) \\
682.8 \\
(2 \mathrm{M}+23)\end{array}$ & 329.2 & - & 5-OMe tectorigenin \\
\hline & 21.14 & 260 & 330 & 331.2 & $\begin{array}{c}353.1 \\
(\mathrm{M}+23) \\
682.9 \\
(2 \mathrm{M}+23)\end{array}$ & 329.2 & - & 7-OMe tectorigenin \\
\hline & 21.95 & - & & ND & - & ND & - & ND \\
\hline & 23.36 & 360 & 600 & 601.2 & $623(M+23)$ & 599.4 & - & $\begin{array}{c}\text { Kaempferol 3-0- (2' } \\
\text { galloyl)- } \\
\text { glucopyranoside }\end{array}$ \\
\hline
\end{tabular}




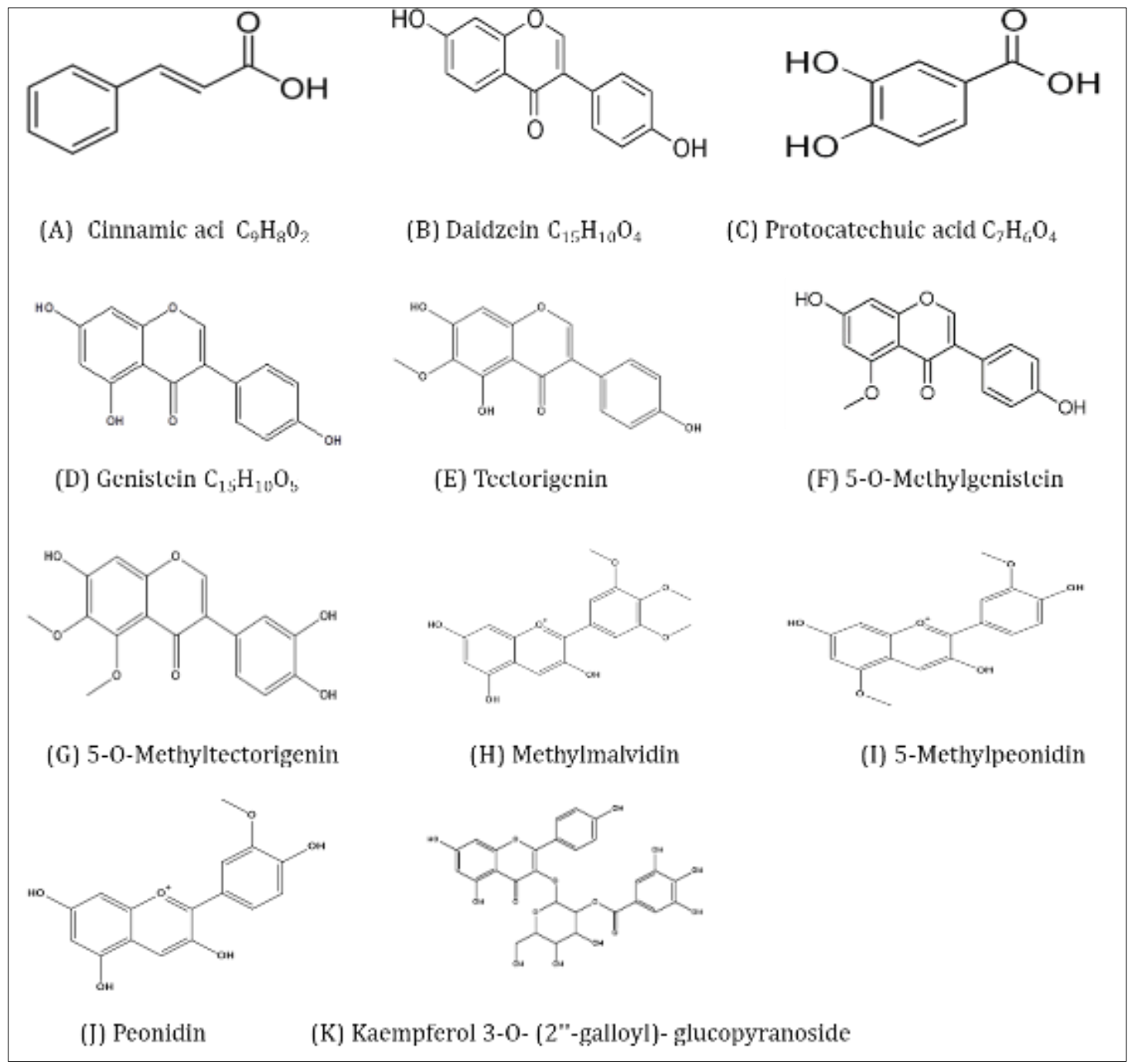

Figure 4 Chemical structure of detected compounds

\section{Discussion}

The DPPH test provides information on the reactivity of compounds with a stable free radical DPPH that gives a strong absorption band at $517 \mathrm{~nm}$ in the visible region. Ascorbic acid was used as the standard antioxidant drug mostly because of its availability in different food sources and ease of standardization. The ethyl acetate and butanol fractions diminished the deep violet color of DPPH to light yellow which is a proof of their antioxidant activity, with ethyl acetate fraction showing better activity. A previous work by Agbafor [7] revealed that the aqueous extract of $V$. doniana leaves showed a concentration-dependent inhibition of DPPH which was not significantly different from those of ascorbic acid. The FRAP results show that the ethyl acetate and butanol fractions exhibited moderate antioxidant activity when compared with the standard ascorbic acid by reducing $\mathrm{Fe}^{3+}$ in the solution to $\mathrm{Fe}^{2+}$ through electron transfer [17]. These results are indicative of the presence of compounds that are capable of donating hydrogen atom and/or transferring electrons to free radicals thus inhibiting/reducing them as the case may be.

Serum levels of ALT, AST and ALP increased significantly $(\mathrm{p}<0.05)$ following treatment with $\mathrm{CCl}_{4}$, thus suggestive of hepatic tissue damage. $\mathrm{CCl}_{4}$-induced hepatotoxicity is commonly used experimentally for the study of effects of medicinal plants and drugs [18]. The most common enzymes employed as indicators of hepatocellular damage are ALT, AST and ALP. Any damage to the liver results in increased plasma activities of these enzymes. Increases in these enzyme's activities are directly proportional to the extent of liver damage [19]. According to Kwo et al. [20], abnormalities of liver enzymes present typically as either cholestasis or hepatocellular injury. Cholestatic injury is indicated by a disproportionate elevation in ALP relative to AST and ALT while hepatocellular injury is indicated by a disproportionate elevation of AST and ALT relative to ALP. It can thus be inferred that administration of $\mathrm{CCl}_{4}$ in mice resulted in hepatocellular injury as indicated by the disproportionate elevation of ALT and AST relative to ALP. The 
plant extracts administered were able to significantly reduce the values of ALP in a dose-dependent manner indicating reversal of oxidative stress.

SOD is an important antioxidant front-line defense against reactive oxygen species (ROS) - mediated injury found in almost all living organisms [21]. SOD catalyzes the dismutation of superoxide radical $\left(\mathrm{O}_{2}{ }^{-}\right)$into oxygen and hydrogen peroxide. The marked increase in SOD activity recorded in the butanol fraction and ethyl acetate fraction treated groups indicates strong antioxidant potential. In the event of oxidative stress in the cells, free radicals escape from the oxidant system and attack the unsaturated fatty acids thus altering the cell membrane structure. This reaction is called lipid peroxidation and is one of the main consequences of oxidative stress. MDA is a useful oxidative stress marker and the final product of lipid peroxidation [22]. Reduction in the level of MDA is thus a measure of antioxidant potential of exogenously administered compounds. We observed a marked reduction in the concentration of MDA following administration of ethyl acetate and butanol fractions of Vitex doniana on animals previously exposed to $\mathrm{CCl}_{4}$. This is a strong indication of the antioxidant activity of these fractions of Vitex doniana fruits extracts.

HPLC-DAD and LC-MS are very powerful analytical tools. These analyses were carried out to ascertain the identities of bioactive compounds that may be responsible for the biological activities observed in the plant. According to Varadarajan [23], the biological activities of medicinal plants may be related to their secondary metabolite or phytochemical constituents. The butanol fraction contains the bulk of the phytoconstituents as seen in the HPLC chromatograms. Thus, the constituents of the fruit could be more polar in nature. Cinnamic acid (identified from the ethylacetate fraction) belongs to a class of non-flavonoids known as phenolic acids and is classified as an unsaturated carboxylic acid. According to Alexandru and Alina [23], cinnamic acids are known to have higher levels of reactive oxygen scavenging activity. Several authors confirmed the antioxidant activity of phenolics using assay methods such as ABTA radical cation, DPPH radical scavenging assay, $\beta$-carotene-linoleic acid, and inhibition of lipid peroxidation induced by superoxide anion radical [25-27]. Protocatechuic acid (dihydroxy benzoic acid) which is also a phenolic acid and has been reported to show better antioxidant activity in vitro compared to trolox by chelating metal transition ions as well as scavenging free radicals via donation of hydrogen atom or electron [28].

Other compounds detected from both HPLC-DAD assay and LC-MS of the butanol sub-fractions belong to a class of polyphenolics called isoflavones. Previous studies on polyphenolic flavonoid structures have shown that the presence of phenolic hydroxyl groups and their structural arrangements contribute to their antioxidant activity through their $\mathrm{H}$ donating properties $[29,30]$. Tectorigenin is a methoxyisoflavone, that is, an isoflavone substituted by a methoxy group at position 6 and hydroxy groups at positions 5, 7 and 4' respectively. Naturally occurring tectorigenin has been shown to have reasonable antioxidant activity both in vivo and in vitro.

Jung [31] reported that tectorigenin and tectoridin isolated from the rhizomes of Belamcanda chinensis showed in vivo antioxidative effects by reversing carbon tetrachloride-induced hepatotoxicity in rats. These results were got by investigating the activities of antioxidant enzymes. According to Bors et al[32], the required structural criteria for antioxidant and high radical-scavenging activities of flavonoids include the ortho-dihydroxyl groups (catechol substructure) in the B-ring or the A-ring, the 3-hydroxyl group in the C-ring, and the 2,3-double bond in conjugation with 4-oxo function (carbonyl group) in the C-ring; and finally, the additional presence of both 3-, 5- and 7-hydroxyl groups. Kaempferol-3-0-(2"-galloyl)-glucopyranoside contains the catechol structure in the A ring, the carbonyl function in the $\mathrm{C}$ ring thus responsible for its antioxidant activity. Malvidin and peonidin are anthocyanidins that have been shown to possess antioxidant properties [33,34]. The result of acute toxicity study revealed no lethality or toxic reactions in mice at any of the selected doses, with $L_{50}$ above $5000 \mathrm{mg} / \mathrm{kg}$. This means that the fruit extract of $V$. doniana is relatively non- toxic and safe for human consumption

\section{Conclusion}

The present study revealed the antioxidant potential of fruits of $V$. doniana which may serve as a promising plant in oxidative stress elimination. It also established its toxicological profile. This may explain the ethnobotanical uses of $V$. doniana fruit in management of a wide range of ailments from dysentery to wound healing. The fractions of $V$. doniana fruit demonstrated both in vivo and in vitro antioxidant activities. The flavonoids identified in fractions of Vitex doniana fruit may be connected to the antioxidant activity observed. The results compared quite favorably with those found in literature. 


\section{Compliance with ethical standards}

\section{Acknowledgments}

The authors are grateful to Prof. Dr. Peter Proksch of the Institute of Pharmaceutical Biology and Biotechnology, Heinrich-Heine Universität Düsseldorf, Germany in whose laboratory the HPLC-DAD and LC-MS analyses were carried out.

\section{Disclosure of conflict of interest}

The author declares no conflict of interest.

\section{References}

[1] Droge W. Free radicals in the physiological control of cell function-Review. Physiol. Rev. 2002; 82: 47-95.

[2] Miller AL. Antioxidant flavonoids: Structure, function and clinical usage. Alt. Med. Rev. 1996; 1:103-111.

[3] Wolfender JL, Queiroz EF, Hostettmann K. The importance of hyphenated techniques in the discovery of new lead compounds from nature. Expert Opin Drug Discov. 2006; 1(3):237-260.

[4] Sarker SD, Nahar L. An introduction to natural products isolation. In: Sarker, S.D.; Nahar, L. editors. Natural Products Isolation, 3rd edition. New Jersey: Humana Press/Springer-Verlag. 2012; 1-26.

[5] Okigbo NR. Fermentation of black plum (Vitex doniana) juice for production of wine. Fruits. 2003; 58(6): 363369.

[6] Orwa C., Mutua A., Kindt R, Jamnadass R, Simons A. Agroforestree Database: a tree reference and selection guide version 4.0 World Agrofor. Cent., Kenya. 2009.

[7] Agbafor KN, Nwachukwu N. Phytochemical analysis and antioxidant property of leaf extracts of Vitex doniana and Mucuna pruriens. Biochem Res Int. 2011; 1-4.

[8] Amah UJ, Okogeri O. Nutritional and phytochemical properties of Wild Black Plum (Vitex doniana) seed from Ebonyi state. Int. J. of Hort. 2019; 3(1):32-36.

[9] Agbede J0, Ibitoye AA. Chemical composition of black plum (Vitex doniana): An under-utilized fruit. J. of Food, Agr. \& Env. 2007;5(2):95-96.

[10] Okpongete CE, Okoye NN, Ajaghaku DL, Ngwoke KG, Nworu CS, Okoye FBC. Ellagic acid derivative and other compounds from Alchornea cordifolia root bark exhibited strong antioxidant and antimicrobial activities. Afr. J. Pharm. Res. \& Dev. 2016; 8(2):108-113.

[11] Benzie IF, Strain JJ. The ferric reducing ability of plasma (FRAP) as a measure of antioxidant power: the FRAP assay. Anal Biochem. 1996;239(1):70-76.

[12] Lorke D.A new approach to practical acute toxicity. Arch. Toxicol. 1983; 53:275-289.

[13] Reitman S, Frankel S. A colorimetric method for the determination of serum glutamic oxaloacetic and glutamic pyruvic transaminases. Am. J. Clin. Pathol.1957; 28:56-63

[14] Roy AV. Rapid method for determining alkaline phosphatase activity in serum with thymolphthalein monophosphate. Clin. Chem. 1970; 16(5):431-436.

[15] Misra HP, Fridovich I. The role of superoxide anion in the autoxidation of epinephrine and a simple assay for superoxide dismutase. J Biol Chem. 1972;247(10):3170-3175.

[16] Gutteridge JM, Wilkins S. Copper-dependent hydroxyl radical damage to ascorbic acid: formation of a thiobarbituric acid-reactive product. FEBS Lett. 1982; 137:327-340.

[17] Zhong Y, Shahidi F. Antioxidants: principles and applications. In: Shahidi F. Handbook of antioxidants for food preservation. Woodhead publishing. 2015; 1-15.

[18] Ahsan MR, Islam KM, Bulbul I.J, Musaddik MA, Haque E. Hepatoprotective activity of methanol extract of some medicinal plants against carbon tetrachloride-induced hepatotoxicity in rats. Euro J Sci Res. 2009; 37(2):302310. 
[19] Chatterjea MN \& Rana S. Liver function tests. In Textbook of Medical Biochemistry. Jaypee Brothers Medical Publishers Ltd, New Delhi. 2005.

[20] Kwo PY, Cohen SM, Lim JK. ACG Clinical Guideline: Evaluation of abnormal liver Chemistries. Am J, Gastroenterol 2017;112:18-35

[21] Kangralkar VA, Patil SD, Bandivadekar RM. Oxidative stress and diabetes. A review. Intl J Pharm Appl. 2010;1(1): 38-45.

[22] Balut M, Selek S, Gergerlioglu HS, Savas HA, Yilmaz HR, Yuce M. Malondialdehyde levels in adult attention-deficit hyperactivity disorder. J Psychiatry Neuerosci. 2007; 32:435-438.

[23] Varadarajan P, Rarhinaswamy G, Asirvatahm D. Antimicrobial properties and phytochemical constituents of Rheo discolor. Ethnobotanical Leaflet. 2008; 12:841-845.

[24] Alexandru MG, Alina MH. Value-added ingredients and enrichments of beverages. The Science of Beverages.2019; 14.

[25] Karamać M, Bucinski A, Pegg RB, Amarowicz R. Antioxidant and antiradical activity of ferulates. Czech J. Food Sci.2005;23: 64-68.

[26] Karamać M, Koleva L, Kancheva VD, Amarowicz R. The Structure-Antioxidant Activity Relationship of Ferulates. $2017 ; 22(4): 527$.

[27] Nenandis N, Zhang HY, Tsimidou MZ. Structure antioxidant activity relationship of ferulic acid derivatives: Effect of carbon side chain characteristic group. J. Agric. Food. Chem.2003; 51:1874-1879.

[28] Anwuchaepe AU, Onyegbule FA, Ajaghaku DL, Nwafor FI, Okoye FB. Evaluation of the in vivo antioxidant, toxicological and chromatographical profiling of leaf extract and fractions of Crescentia cujete Linn. (Bignoniaceae). Asian Pac. J. Health Sci., 2017; 4(3):43-54.

[29] Rice-Evans CA, Miller NJ, Paganga G. Structure-antioxidant activity relationships of flavonoids and phenolic acids. Free Radical Biology and Medicine.1996; 20(7): 933-956.

[30] Okoye FBC,Osadebe PO. A new anti-inflammatory flavonol glycoside from Alchornea floribunda leaves. Natural Product Research. 2010; 24 (3):266-273.

[31] Jung SH, Lee YS, Lim SS, Lee S, Shin, KH, Kim YS. Antioxidant activities of isoflavones from the rhizomes of Belamcanda chinensis on carbon tetrachloride-induced hepatic injury in rats. Arch Pharm Res. 2004; 27:184-188.

[32] Bors W, Michel C, Stettmaier K. Structure-activity relationships governing antioxidant capacities of plant polyphenols. Methods in Enzymology. 2001; 335:166-180.

[33] Mosquera RA. A computational study of the acidity dependence of radical-scavenging mechanisms of anthocyanidins. The J Phys Chem B. 2010; 114:9706-9712

[34] Mosquera RA, Estévez L.Molecular structure and antioxidant properties of delphinidin. The J Phys Chem A. 2008; 112:10614-10623.

\section{Supplementary material}

Evaluation of the antioxidant potentials of extract and fractions of Vitex doniana fruit and identification of the bioactive metabolites using HPLC-DAD-MS analysis. 


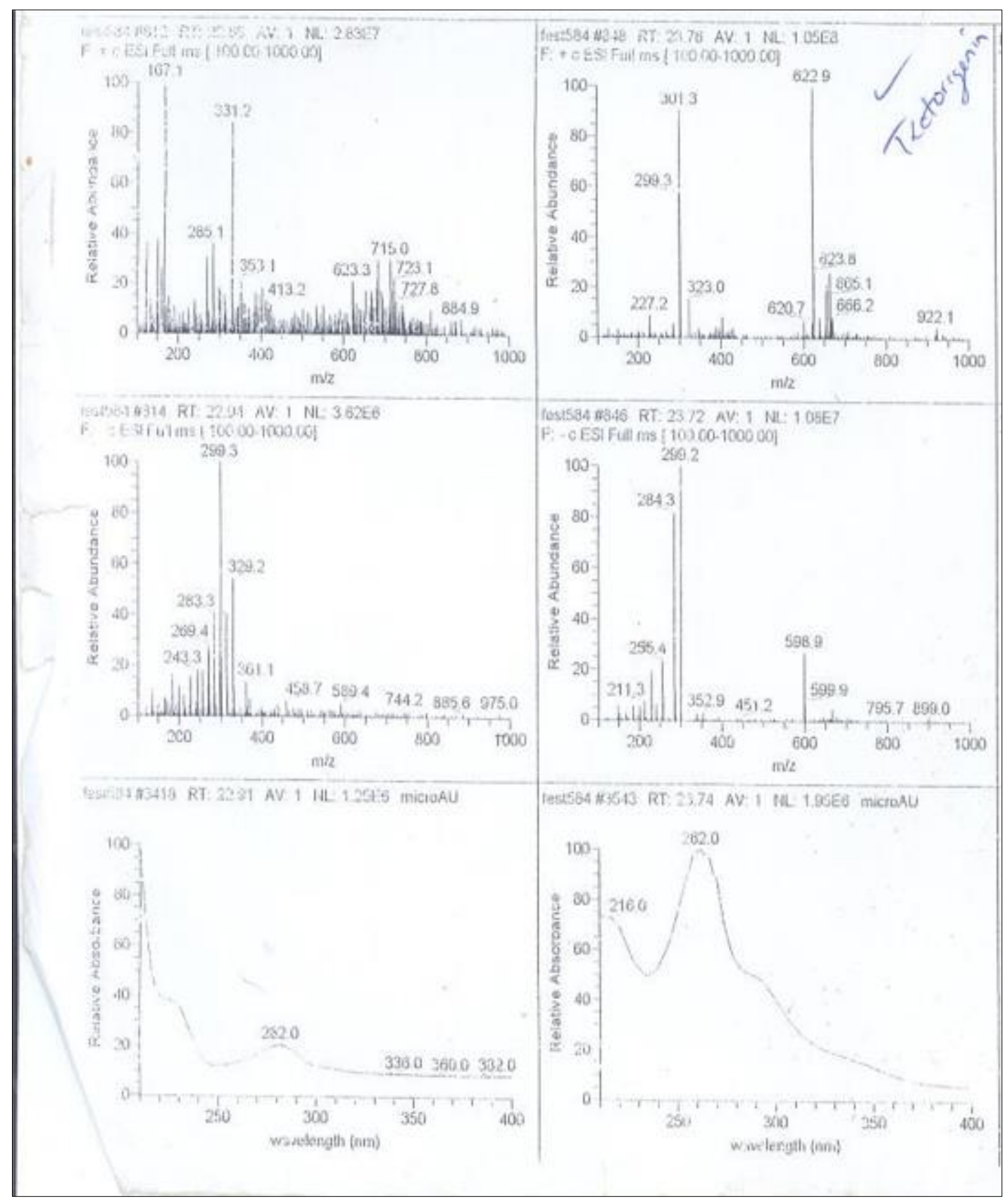

Figure S1 LC-MS spectra of VTX-F4 showing ionizations (pseudomolecular and fragment ions) in both the positive and negative modes and the accompanying UV spectra of the detected compounds 


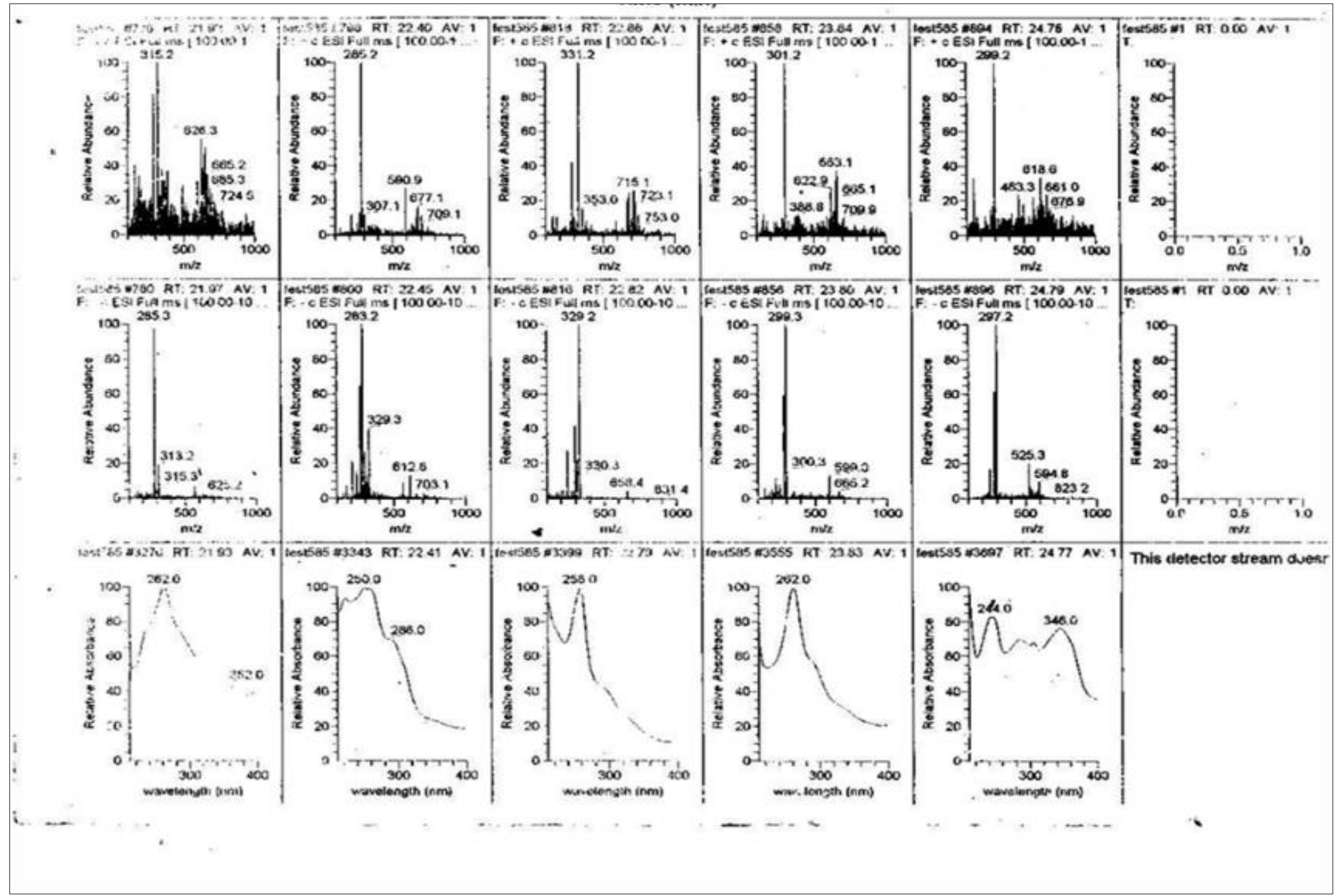

Figure S2 LC-MS spectra of VTX- F5 showing ionizations (pseudomolecular and fragment ions) in both the positive and negative modes and the accompanying UV spectra of the detected compounds 
GSC Biological and Pharmaceutical Sciences, 2021, 17(01), 160-175

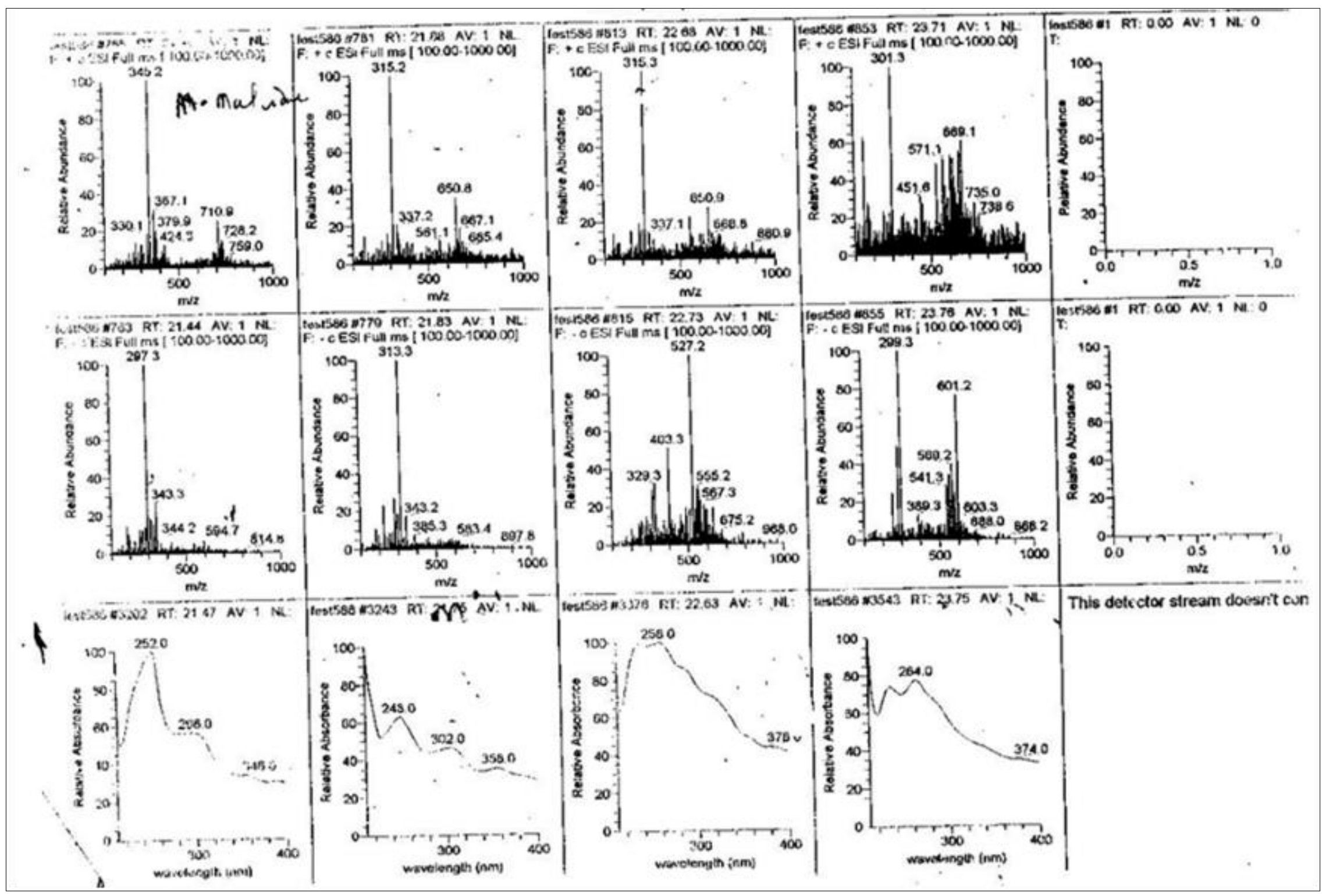

Figure S3 LC-MS spectra of VTX-F 6 showing ionizations (pseudomolecular and fragment ions) in both the positive and negative modes and the accompanying UV spectra of the detected compounds 
GSC Biological and Pharmaceutical Sciences, 2021, 17(01), 160-175

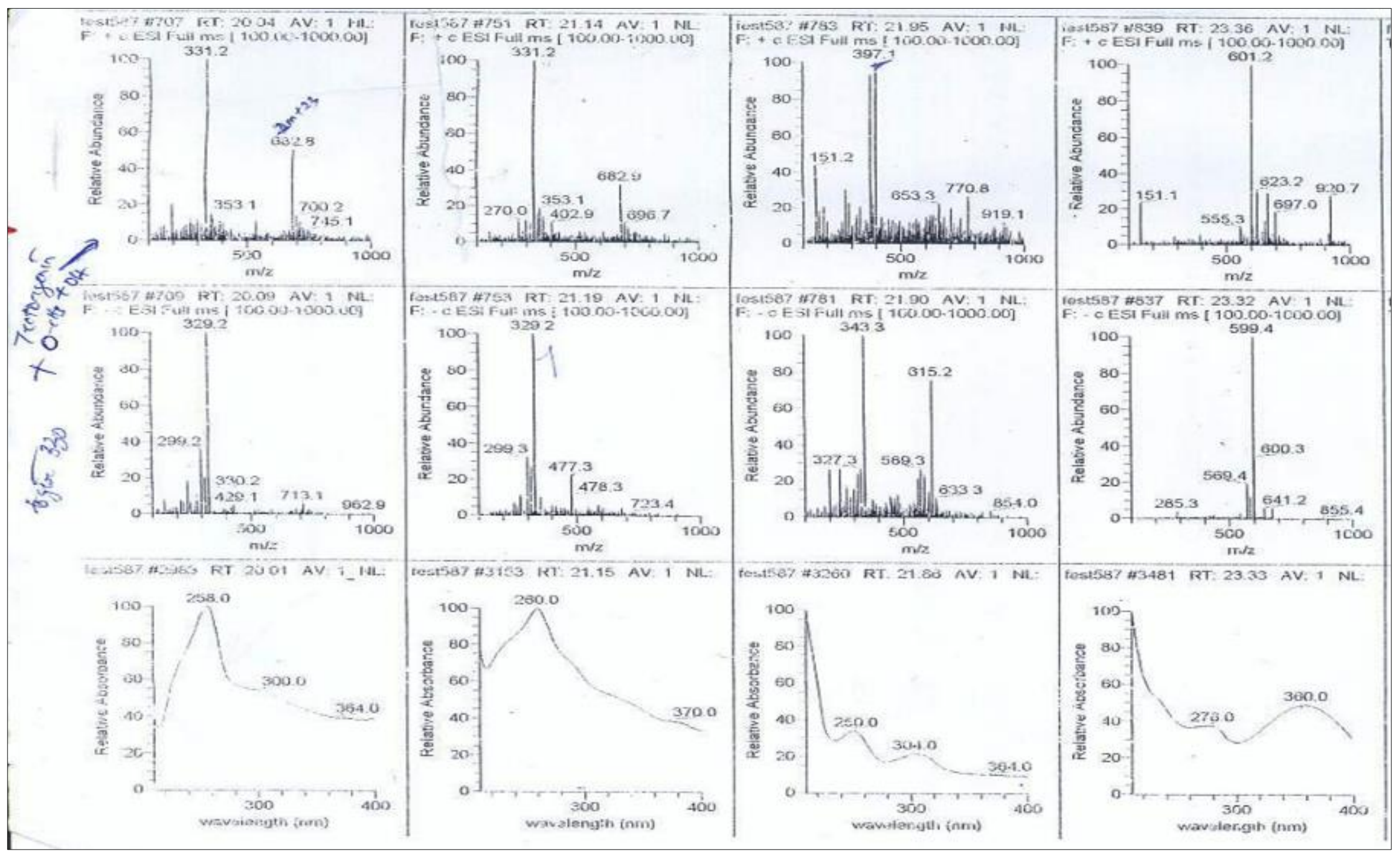

Figure S4 LC-MS spectra of VTX-F7 showing ionizations (pseudomolecular and fragment ions) in both the positive and negative modes and the accompanying UV spectra of the detected compound 